\title{
4E Analysis of Integrated MHD-Combined Cycle
}

\author{
M.A. Esmaeilzadehazimi ${ }^{1}$, M. H. Khoshgoftar Manesh ${ }^{2,3, *}$, B. Bakhtiari Heleyleh ${ }^{1}$, H. Vazini Modabber ${ }^{2,3}$ \\ ${ }^{1}$ Department of Energy Engineering, Faculty of Environment and Energy, Science and Research Branch, Islamic Azad \\ University, Tehran, Iran \\ ${ }^{2}$ Division of Thermal Sciences and Energy Systems, Department of Mechanical Engineering, Faculty of Technology \& \\ Engineering, University of Qom, Qom, Iran \\ ${ }^{3}$ Center of Environmental Research, University of Qom, Iran \\ E-mail: m.khoshgoftar@qom.ac.ir ; mh.khoshgoftar@gmail.com
}

Received 27 May 2019, Revised 25 August 2019, Accepted 24 September 2019

\begin{abstract}
In recent years, there have been increasing studies on topping cycles of combined cycle power plants with very high working temperature (about $3000 \mathrm{~K}$ ). One of the thermal cycles, which have the ability to work in this temperature range, is MHD-Magneto hydrodynamic- cycle. MHD cycle can operate in two states. One state is the open cycle, and the other one is the close cycle. In both mentioned states there is a large amount of waste heat that can be recovered. It seems that the use of recovered heat from MHD cycles as the heat source for a gas turbine cycle namely Brayton according to their working temperature is promising. The objective of this study focused on energetic, exergetic, exergoeconomic and environmental (4E) analysis and evaluation of a proposed cycle based on the integration of combined cycle with MHD generator as the topping cycle. In this regard, the thermodynamic simulation of the plant has been performed. To verify of the thermodynamic simulation, the results have been compared with Thermoflex software and the data in the literature. In addition, exergetic, exergoeconomic, and environmental modeling and evaluation have been performed through computer code. The results show the good accuracy of the thermodynamic simulation for the integrated system. Also, the proposed cycle has a higher efficiency with the lower cost of exergy destruction and lower emission.
\end{abstract}

Keywords: MHD generator; brayton cycle; rankine cycle; combined cycle; exergy.

\section{Aims and Scope}

Current power generation methods are not very efficient and may not even be adequate to keep pace with increasing demand. Among the new methods of energy conversion is the production of electrical energy from the kinetic energy of plasma (ionized gas) in magnetohydrodynamic or MHD generators. In these generators, by flicking the plasma in a vertical plane perpendicular to a magnetic field, according to a phenomenon called Faraday, an electric field is induced in a direction perpendicular to two directions of the fluid flow vector and magnetic field vector. The only difference between the generator is the use of plasma rather than moving parts as the main advantage. It also has a relatively small weight compared to conventional generators can be used in the aviation and offshore industries.

The modeling of a steam cycle with an MHD generator is presented by Aspnes et al. The schematic diagram of the integrated system and the overall design of this cycle are explained. The automatic control of this cycle is an analysis that is important in this work; this is valuable in terms of overall cycle modeling. Main components including the combustion chamber, nozzle, turbine, and boiler have been modeled, and state equation has been developed for each of them [1].

Polarization is a process of creating two poles in a material. Chaturvedi [2] proposed on polarization and charge effect on the efficiency of the MHD generator. An MHD generator was considered, and then an initial fluid analysis was attempted on this generator. Then, by using polarization have been tried to increase the rate of energy production and increase the efficiency of the plant.

An overview of the performance and history of the use of the MHD generator has been investigated by Malghan. The rate of use of the MHD generator in different parts of the world and the amount of power generation are shown on different charts and tables [3].

Ishikawa [4] focused on the MHD generator effects in a power generation plant. The MHD generator is fully described, and then a cyclical study of coal-fired power plants and MHD generators has been investigated. Different processes of this cycle have been analyzed and, the results are presented. One of the main problems in this leak cycle is a lot of various issues. Some of the optimizations have been attempted to reduce the amount of leakage in the cycle [4].

A full-power generation cycle has been studied by Lemnean et al., which is also linked to the MHD generator. This generator has recorded various experimental data in different working conditions. These empirical data are presented in this paper that can be used to compare simulation results in any power generation plant with this information [5].

The MHD generator has a great impact on increasing the efficiency of thermal power cycles. For this purpose, Ishikawa et al. are focused on a Brayton cycle or a gas turbine cycle that has been connected to an MHD generator. An initial thermodynamic analysis has been made on the equipment of this cycle. The results show that in the simple MHD plant the efficiency can be in the range of $39 \%$ to $3.6 \%$ 
and gas turbine cycle with MHD generator is has been increased to $54 \%$ to $67.8 \%$ [6].

Ishikawa et al. are proposed to describe how an integrated system, including a power generating unit and an MHD generator, is implemented. The amount of pollutant emissions, especially carbon dioxide, has been investigated in this system. Electricity power generation plant has burnt the coal by high efficiency of $43 \%$, and the MHD generator efficiency is equal to $46 \%$ [7].

Two thermal power plants are connected to the MHD generator by Ishikawa et al. and have been compared with each other for the production of environmental pollution especially carbon dioxide. The first plant has a coal-fired combined cycle, and the second is a combined-cycle steam power plant. The results and relationships in the article are based on thermodynamic and chemical concepts. The cycle efficiency with $\mathrm{CO}_{2}$ recovery has been calculated about $45.3 \%$ [8].

Bhadoria et al. have been tried to use different thermodynamic and fluid relationships to reduce the amount of MHD generators dissipation in different working conditions. The results of the losses in the MHD generator including heat, leakage, and friction not only reduce the amount of outlet power but also degrade it [9].

A general comparison between various types of MHD generators and their combination with power generation cycles has been studied by Kayukawa. Results show that a connection between steam turbine cycle, gas turbine cycle, MHD generator, and gasification unit had the best efficiency in all of the cases that have been studied [10].

A closed cycle with an MHD generator with nozzles and diffusers has been designed by Inui et al. Modeling cycles, and working fluid and thermal analyzes have been done on this cycle. Different parts of the cycle have been described and show that the thermal input is $100 \mathrm{MW}$, but electricity output is $40 \mathrm{MW}$. The intermittent discharge phenomenon has been presented for the first time in this presentation [11].

A power generation cycle with the MHD generator has been investigated by Chen et al. Different thermodynamic relationships have been used to study this cycle. The efficiency of the cycle is calculated using these relationships. Then the effect of heat transfer on the performance of MHD generators has been specifically studied. The irreversibilities including heat transfer in the heat exchanger and compression loss in compressor and expansion loss in the MHD generator have been calculated [12].

Inoue et al. are proposed a variety of MHD generators has been connected to power generation cycles. This model is known as MHD generators for open cycle generators. First, they tried to examine the transient resistance of these generators [13].

Vogin et al. have been tried to explain how this model works from generators, and the relations governing the types of current in this generator are described. The results of this modeling are plotted in the paper. Finally, with some optimizations, the efficiency of this generator has been increased to $52 \%$ [14].

In an MHD generator, high-speed gases pass through the generator, and electricity is produced due to the presence of magnetic plates without any mechanical movement. A power generation cycle close to the combined cycle along with the MHD generator is investigated by Cicconardi et al. The analysis carried out in this article is based on the evaluation of the cycle efficiency. Results show that the best efficiency (up to $60 \%$ ) of the system has been occurred by using the syngas due to better heat recovery in high-temperature region [15].

A variety of thermal power generation cycles have been presented by Sarkar. Briefly, the components of each cycle, the advantages and disadvantages, the mode of operation and other principle features of each cycle are demonstrated. This article is very beneficial for clarifying various cycles. It also delineate a very certain way the equipment of many types of power plants in the world [16].

When heat is produced in a combustion chamber of thermal energy and then supplied to turbine blades and, generators, mechanical work turns into electrical energy. If the heat transfer to the turbine can also be used to generate electrical power, both the system efficiency has increased and, the amount of electrical energy generated has increased. The MHD generates supply this at thermal power plants. Ayeleso et al. have been tried to investigate the effect of adding an MHD generator on thermal cycles [17].

In this paper, by investigating the studies carried out in this area, while introducing magnetic hydrodynamic generators, the challenges of using them to reduce the cost of generating electricity are contemplated.

\section{Case Study \\ 2.1 MHD Generator}

The combined cycle with MHD generator is shown in Figure 1. This cycle consists of an MHD cycle with recovery in the upstream and downstream of the Brayton cycle in the middle and downstream of the MHD cycle and eventually the downstream steam cycle. The air enters a 2-stage compressor at ambient temperature and atmospheric pressure. Then, passing through an intercooler, the temperature decreases that reduces the total amount of compressor operation and thereby increases the efficiency. The cooled air enters the secondary compressor to increase the pressure to target. Compressed and heated air continues to enter the combustion chamber after it is heated in the middle cycle to the temperature of the target. The air at preheated temperature p3 enters the combustion chamber, and the fuel is introduced at the ambient conditions, it should be noted that for the plasma, the operating fluid is airborne. In addition to high temperatures, potassium carbonate $\left(\mathrm{K}_{2} \mathrm{CO}_{3}\right)$ is also required. The mass of the total mass of the fluid entering the MHD nozzle of potassium carbonate is added to the combustion chamber with fuel. The plasma at $3000 \mathrm{~K}$ is introduced into the MHD nozzle with a high Mach number. At the end of the nozzle, we are faced with a decrease in pressure and speed.

\subsection{Brayton and Rankine Cycles}

Brayton's mid-cycle receives the required heat from the MHD's upper hand cycle. The required heat for the gas turbine is $1600 \mathrm{KW}$. Advanced gas turbines with such a temperature can achieve $60 \%$ efficiency in combined cycles. Thus, as in the upstream air cycle, air is compressed into the gas turbine to obtain the required heat in the converter. The output current from gas turbine - Flow 15 - for preheating, enter a converter. The output current of the MHD enters the 
downstream steam turbine after the heat transfer to the middle cycle.

\section{Methodology}

\subsection{Thermodynamic Modeling}

Gas turbines are a mechanical rotary machine receiving and exploiting the released energy from the combustion of fuel with compressed air. Therefore, each gas turbine consists of three independent units, which include the air compressor unit, the combustion chamber unit and, eventually, the power turbine unit.

The mechanical energy derived from the entire process involves a diverse range of applications in various industries, including the use of the resulting mechanical power, the generation of electric current (generators), the compression of the alternating current of fluids (gas compressors) and the propulsive force required for aircraft and others. For calculating thermodynamic properties of each point of the cycle, equations for each component have been listed in Table A (Appendix A).

\subsection{Exergy Analysis}

Many forms of energy have variable qualities. Exergy helps us to define these qualities and to control energy efficiency optimization. Exergy analysis in the design and development of sustainable processes provides the necessary information for long-term planning of resource utilization.

For analyzing the system from the perspective of the exergy concept, we should calculate the physical and chemical exergy in each of the streams by equations [20].

$$
\begin{aligned}
& e x^{P H}=\left(h-h_{0}\right)-T_{0}\left(\mathrm{~s}-\mathrm{s}_{0}\right) \\
& e x^{C H}=\sum x_{k} e \bar{x}_{k}^{C H}+\bar{R} T_{0} \sum x_{k} \ln \left(\mathrm{x}_{k}\right) \\
& e x_{\text {methane }}^{C H}=1.037 \times L H V_{\text {methane }} \\
& \dot{E} x_{k}=\dot{m}_{k} \times e x_{k}
\end{aligned}
$$

Exergy destruction and exergetic efficiency of each component can obtain as follow [20].

$$
\dot{E} x_{D, k}=\dot{E} x_{\mathrm{F}, k}-\dot{E} x_{\mathrm{P}, k}
$$

$$
\psi_{k}=\frac{\dot{E} x_{P, k}}{\dot{E} x_{\mathrm{F}, k}}
$$

For each component, we can introduce some streams as the fuel of that component and some others as the product of component. Table 1 shows the fuel and product of each component in the plant [20].

Table 1. Fuel and product exergy streams of the equipment [20].

\begin{tabular}{lcc}
\hline Component & $\dot{E} x_{F}$ & $\dot{E} x_{P}$ \\
\hline$M H D$ & $\dot{E} x_{7}-\dot{E} x_{8}$ & $\dot{W}_{M H D}$ \\
$A C_{I}$ & $\dot{W}_{A C_{1}}$ & $\dot{E} x_{2}-\dot{E} x_{1}$ \\
$A C_{2}$ & $\dot{W}_{A C_{2}}$ & $\dot{E} x_{4}-\dot{E} x_{3}$ \\
$A C_{3}$ & $\dot{W}_{A C_{3}}$ & $\dot{E} x_{12}-\dot{E} x_{11}$ \\
$C C$ & $\dot{E} x_{5}-\dot{E} x_{6}$ & $\dot{E} x_{7}$ \\
$G T$ & $\dot{E} x_{13}-\dot{E} x_{14}$ & $\dot{W_{G T}}$ \\
Intercooler & $\dot{E} x_{18}-\dot{E} x_{17}$ & $\dot{E} x_{2}-\dot{E} x_{3}$ \\
$H X_{1}$ & $\dot{E} x_{14}-\dot{E} x_{15}$ & $\dot{E} x_{5}-\dot{E} x_{4}$ \\
$H X_{2}$ & $\dot{E} x_{8}-\dot{E} x_{9}$ & $\dot{E} x_{13}-\dot{E} x_{12}$ \\
$S G$ & $\dot{E} x_{9}-\dot{E} x_{10}$ & $\dot{E} x_{19}-\dot{E} x_{18}$ \\
$S T$ & $\dot{E} x_{19}-\dot{E} x_{20}$ & $\dot{W_{S T}}$ \\
Pump & $\dot{W}_{P \text { rump }}$ & $\dot{E} x_{17}-\dot{E} x_{16}$ \\
Condenser & $\dot{E} x_{20}-\dot{E} x_{16}$ & $\dot{E} x_{22}-\dot{E} x_{21}$ \\
\hline
\end{tabular}

\subsection{Exergoeconomic analysis}

The exergy analysis of the above cycles can be appropriately combined with information on economic aspects, including investment, fuel, and repair costs, and calculates the final product price, such as the price of electricity produced. Based on these calculations, the cost of the exergy destroyed of the each component can be estimated and evaluated. Using the results, we can find out the role of component efficiency and cost on the finished product price.

We can calculate the cost rate of the equipment as Eq.(7) [21].

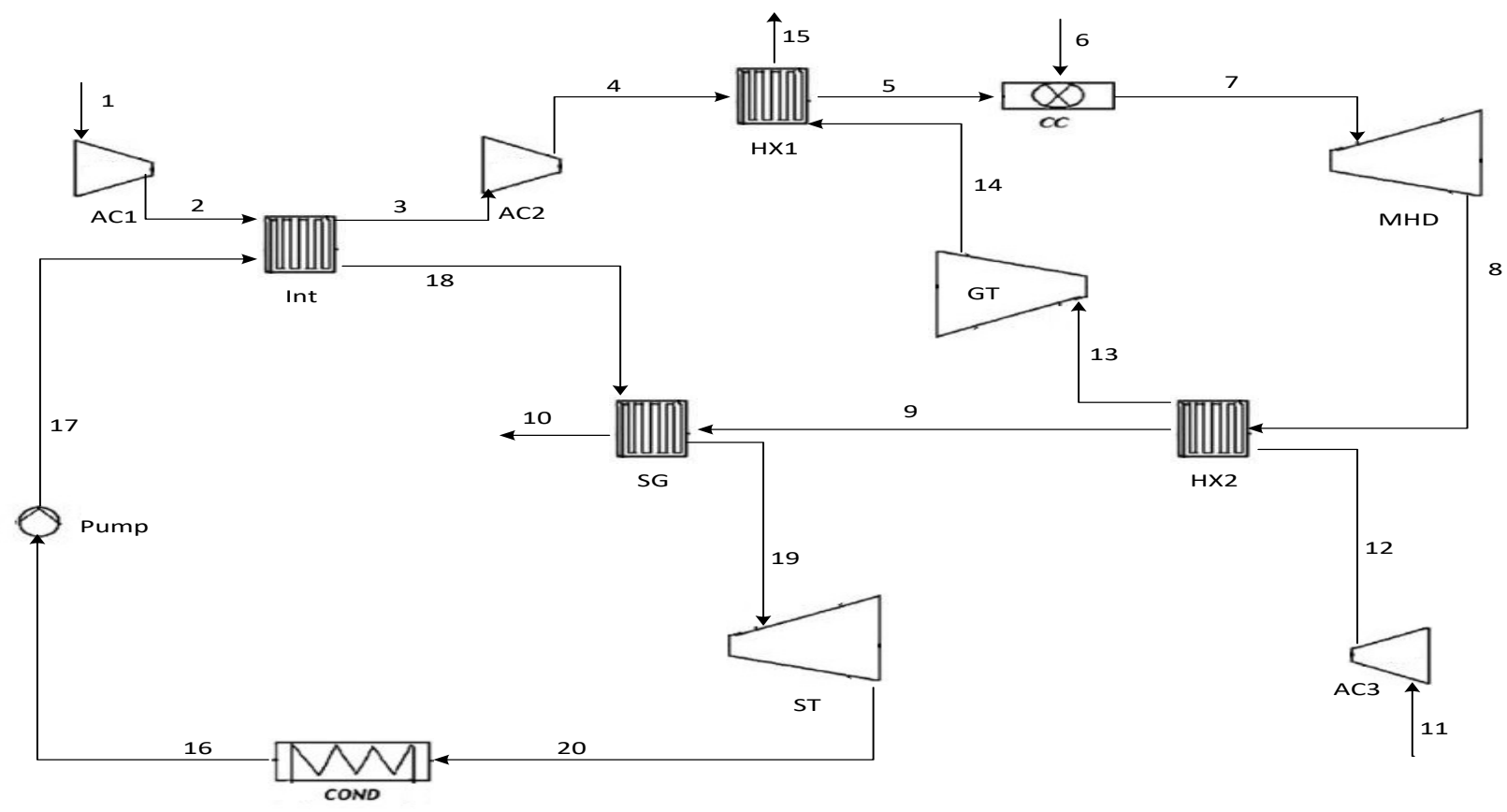

Figure 1. Schematic of combined cycle power plant integrated with MHD 
$\dot{Z}_{k}=\frac{\Phi_{k} \times P E C_{k} \times C R F}{3600 \times n}$

where $\Phi_{k}$ is the maintenance factor : it can be considered $1.06[20,21]$. And $n$ is the plant's life which is considered 25 years [20]. CRF is the capital recovery factor that obtained as Eq. (8) [20].

$C R F=\frac{i \times(1+i)^{n}}{(1+i)^{n}-1}$

We can write the exergoeconomic balance for each component as follow[20].

$$
\begin{aligned}
& \dot{C}_{P, k}=\dot{C}_{F, k}-\dot{C}_{L, k}+\dot{Z}_{k} \\
& \sum_{e} \dot{C}_{e, k}+\dot{C}_{w, k}=\dot{C}_{q, k}-\sum_{i} \dot{C}_{i, k}+\dot{Z}_{k} \\
& \dot{C}_{i}=c_{i} \cdot \dot{E}_{i}
\end{aligned}
$$

where $\dot{C}_{P}$ is the cost rate of product stream of the component. And $\dot{C}_{F}$ is the cost rate of fuel stream of the equipment. $\dot{Z}_{k}$ is the cost rate associated with each component's capital investment rate and operating and maintenance cost.

The cost rate of exergy destruction of the equipment is obtained as Eq. (12) [20].

$$
\dot{C}_{D, k}=c_{F, k} \cdot \dot{E}_{D, k}
$$

The exergoeconomic factor for each component can be calculated as equation 15 [20].

$f_{k}=\frac{\dot{Z}_{k}}{\dot{Z}_{k}+c_{f, k} \dot{E}_{D, k}}$

The relative cost difference of the equipment is the other parameter that obtained as follow [20].

$$
r_{k}=\frac{c_{\mathrm{P}, k}-c_{F, k}}{c_{F, k}}=\frac{1-\psi_{k}}{\psi_{k}}+\frac{\dot{Z}_{k}}{c_{f, k} \dot{E}_{\mathrm{P}, k}}
$$

The purchase equipment cost of the components can be calculated from [21, 23-25]. Purchase cost of the MHD with updated cost index is calculated using [26] and [27].

\subsection{Environmental Analysis}

Power generating units need not only large investments but also natural resources, such as fossil fuels, which have permanent effects on the environment. Air pollution caused by power plants includes the release of carbon monoxide, sulfur dioxide, nitrogen oxides. At present, about $67 \%$ of worldwide emissions are produced from fossil fuels. Direct emissions from fossil fuel plants depend on thermal efficiency, the method of operation, technology type, and carbon content fuels.

The following equation is used to calculate the amount of emission of pollutants: [28]

$$
E=A F \times E F \times\left(1-\frac{E R}{100}\right)
$$

where $E$ is the amount of emission, $A F$ is the amount of fuel consumed, EF is the pollutant emission factor, $E R$ is effectiveness of the emission reduction technology and also the efficiency of the emission reduction system, which is zero because it is not used in the existing design.

So the relation (10) becomes simple: $E=A F \times E F$

The $E F$ value of these references can be deduced from $[29,30]$. In addition its value has three parameters: fuel, that is natural gas, the type of pollutant (carbon monoxide, $\mathrm{NO}_{\mathrm{x}}$, carbon dioxide) and at the end the type of process.

Using [29,30], the following values are extracted:

$E F_{C O}=20[\mathrm{~g} / \mathrm{GJ}]$

$E F_{N O_{x}}=48[\mathrm{~g} / \mathrm{GJ}]$

To calculate carbon dioxide emissions, we use the following equation [28]:

$E_{\mathrm{CO}_{2}}=\frac{Q_{\text {fuel }}}{N H V_{\text {fuel }}} \cdot \frac{C \%}{100} \cdot \alpha$

where C\% is the percentage of carbon in the fuel, $Q_{\text {fuel }}$ is the heat released by the fuel in the combustion chamber and $\mathrm{C}$ is carbon content. For natural gas, the percentage of carbon composition is 19.9 percent. The ratio of the molar carbon dioxide to the molar carbon is 3.67. $\alpha=$ ratio of molar masses of $\mathrm{CO}_{2}$ and $\mathrm{C}$, and $\mathrm{NHV}$ is the net heating value of fuel, which is the same as the reference for natural gas.

\section{Results and Discussion \\ 4.1 Thermodynamic Results}

The case study cycle is modeled in MATLAB and Thermoflex software. The thermodynamic properties

\begin{tabular}{|c|c|c|c|c|c|c|c|c|c|}
\hline \multirow[b]{2}{*}{ Streams } & \multicolumn{3}{|c|}{$\dot{m}[k g / s]$} & \multicolumn{3}{|c|}{$T[K]$} & \multicolumn{3}{|c|}{$P[k P a]$} \\
\hline & MATLAB & Thermoflex & Error [\%] & MATLAB & Thermoflex & Error [\%] & MATLAB & Thermoflex & Error [\%] \\
\hline 1 & 17.34 & 17.34 & 0.0 & 300.00 & 300 & 0.0 & 100.00 & 100 & 0.00 \\
\hline 2 & 17.34 & 17.34 & 0.0 & 494.60 & 496.5 & 0.38 & 500.00 & 500 & 0.00 \\
\hline 3 & 17.34 & 17.34 & 0.0 & 354.16 & 355.3 & 0.32 & 495.00 & 495 & 0.00 \\
\hline 4 & 17.34 & 17.34 & 0.0 & 440.35 & 441.5 & 0.26 & 990.00 & 990.1 & 0.01 \\
\hline 5 & 17.34 & 17.34 & 0.0 & 827.60 & 879.9 & 5.94 & 980.10 & 980.3 & 0.02 \\
\hline 6 & 0.998 & 0.93 & 6.24 & 300.00 & 300 & 0.00 & 2068 & 2068 & 0.00 \\
\hline 7 & 18.34 & 18.28 & 0.30 & 3000.00 & 3000 & 0.00 & 960.50 & 961.1 & 0.06 \\
\hline 8 & 18.34 & 18.28 & 0.30 & 2096.60 & 2089.1 & 0.36 & 102.03 & 103 & 0.94 \\
\hline 9 & 18.34 & 18.28 & 0.30 & 1259.30 & 1161.4 & 8.43 & 101.01 & 101.9 & 0.95 \\
\hline 10 & 18.34 & 18.28 & 0.30 & 418.05 & 422.6 & 1.08 & 100.0 & 101 & 0.99 \\
\hline
\end{tabular}
including mass flow rate, temperature and pressure of point to point of the cycle are calculated. We compared the results of these two simulation in Table 2.

Table 2. Comparison of main parameters of thermodynamic modeling in Thermoflex with those of first law analysis programed in MATLAB for the material streams. 


\begin{tabular}{cccc|ccc|cccc}
11 & 17.67 & 17.67 & 0.0 & 300.00 & 300 & 0.00 & 100.0 & 100 & 0.00 \\
12 & 17.67 & 17.67 & 0.0 & 610.23 & 613.1 & 0.47 & 1000.0 & 999.8 & 0.02 & 989.9 \\
13 & 17.67 & 17.67 & 0.0 & 1623.00 & 1623 & 0.00 & 990.0 & 0.01 & 9.01 \\
14 & 17.67 & 17.67 & 0.0 & 915.45 & 983.6 & 6.93 & 101.01 & 101 & 0.01 \\
15 & 17.67 & 17.67 & 0.0 & 535.37 & 562.9 & 4.89 & 100.0 & 100 & 0.00 \\
16 & 5.75 & 6.00 & 4.17 & 318.82 & 319 & 0.06 & 10.0 & 10.0 & 0.00 \\
17 & 5.75 & 6.00 & 4.17 & 319.05 & 319.8 & 0.23 & 4000.0 & 4000 & 0.00 \\
18 & 5.75 & 6.00 & 4.17 & 420.09 & 432.7 & 2.91 & 4000.0 & 4000 & 0.00 \\
19 & 5.75 & 6.00 & 4.17 & 911.57 & 774 & 17.77 & 4000.0 & 4000 & 0.00 \\
20 & 5.75 & 6.00 & 4.17 & 318.81 & 319.00 & 0.06 & 10.0 & 10 & 0.00 \\
\hline
\end{tabular}

The maximum error between the two software has occurred in calculating the temperature of stream number 19 . Other errors are in an acceptable level.

For verifying the main parameters of these two methods of simulation we compared them in Table 3. The main parameters consist of the power consumed or produced in each compressor, pump, turbine and the heat duty of each heat exchanger.

Table 3. Comparison of main parameters of thermodynamic modeling in Thermoflex with those of first law analysis programed in MATLAB for the components

\begin{tabular}{lccc}
\hline & MATLAB & Thermoflex & Error [\%] \\
\hline $\mathrm{W}_{\mathrm{AC} 1}[\mathrm{KW}]$ & 3389.1 & 3500 & 3.17 \\
$\mathrm{~W}_{\mathrm{AC} 2}[\mathrm{KW}]$ & 1500.9 & 1534.3 & 2.18 \\
$\mathrm{~W}_{\mathrm{AC} 3}[\mathrm{KW}]$ & 5504.7 & 5740 & 4.10 \\
$\mathrm{~W}_{\mathrm{MHD}}[\mathrm{KW}]$ & 19390 & 19163 & 1.18 \\
$\mathrm{~W}_{\mathrm{ST}}[\mathrm{KW}]$ & 7222 & 6842 & 5.55 \\
$\mathrm{~W}_{\mathrm{GT}}[\mathrm{KW}]$ & 12555 & 13610 & 7.75 \\
$\mathrm{Q}_{\mathrm{int}}[\mathrm{KW}]$ & 2445.9 & 2527.8 & 3.24 \\
$\mathrm{Q}_{\mathrm{HX} 1}[\mathrm{KW}]$ & 6744.1 & 7221 & 6.60 \\
$\mathrm{Q}_{\mathrm{HX} 2}[\mathrm{KW}]$ & 17637 & 18891 & 6.64 \\
$\mathrm{Q}_{\mathrm{SG}}[\mathrm{KW}]$ & 18055 & 16688 & 8.19 \\
$\mathrm{Q}_{\mathrm{cond}}[\mathrm{KW}]$ & 13305 & 12010 & 10.78 \\
$\mathrm{~W}_{\mathrm{Pump}}[\mathrm{MW}]$ & 25.62 & 28.21 & 9.18 \\
\hline
\end{tabular}

The maximum error is in the heat duty of condenser calculation. Also, for the verification of MHD equipment, the simulation results in this study and the results of a study by Nimvari et al. have been compared in Table 4 that show the accuracy of the calculations [31].

Table 4. Comparing the results of Matlab, Thermoflex and the study of Nimvari et al. [31] for MHD

\begin{tabular}{lcccc}
\hline Parameter & Unit & MATLAB & Thermoflex & $\begin{array}{c}\text { Nimvari } \\
\text { et al }\end{array}$ \\
\hline $\begin{array}{l}\text { Inlet } \\
\text { Temperature }\end{array}$ & $\mathrm{K}$ & 3000 & 3000 & 3000 \\
$\begin{array}{l}\text { Outlet } \\
\text { Temperature }\end{array}$ & $\mathrm{K}$ & 2096.6 & 2089.1 & 2200 \\
$\begin{array}{l}\text { Power Produced } \\
\text { Mass Flow Rate }\end{array}$ & $\mathrm{kW}$ & 19390 & 19163 & 18824.4 \\
\hline
\end{tabular}

\subsection{Exergy Results}

In the analysis of exergy, in addition to the quantity of energy, its quality has also been taken into consideration. We calculate the exergy destruction rate in each component of the cycle as Table 5. Exergy analysis is conducted in the industrial environment for more efficient use of energy.
Exergy depends on the state of both the system and the environment. The internal energy of a system is always measured by a constant reference state and therefore the state function. The destruction of exergy in a cycle is the sum of the exergies destroyed in the entire cycle of the process.

The results of the exergy analysis recorded in Table 5 and Figure 2 that show that the combustion chamber and the steam generator have a high exergy degradation rate and can be modified to improve the efficiency of the system.

Table 5. Exergy destruction rate and exergetic efficiency of the equipment.

\begin{tabular}{lcc}
\hline Component & $E x_{D}[K W]$ & $\psi[\%]$ \\
\hline Air Compressor 1 & 208.52 & 93.85 \\
Air Compressor 2 & 102.75 & 93.15 \\
Air Compressor 3 & 276.00 & 94.98 \\
MHD & 1271.3 & 93.85 \\
Combustion & 12386 & 79.05 \\
Chamber & 754.75 & 90.54 \\
Steam Turbine & 425.03 & 96.72 \\
Gas Turbine & 266.03 & 62.84 \\
Intercooler & 471.16 & 87.93 \\
Heat Exchanger 1 & 1956.2 & 86.70 \\
Heat Exchanger 2 & 2676.6 & 75.60 \\
Steam Generator & 369.18 & 53.31 \\
Condenser & 2.49 & 90.29 \\
Pump & & \\
\hline
\end{tabular}

\subsection{Exergoeconomic Analysis}

The economic analysis based on the second law of thermodynamics, or the exergy-economic analysis. We calculated the thermodynamic properties of each point and the cost rate of each stream shown in Table 6.

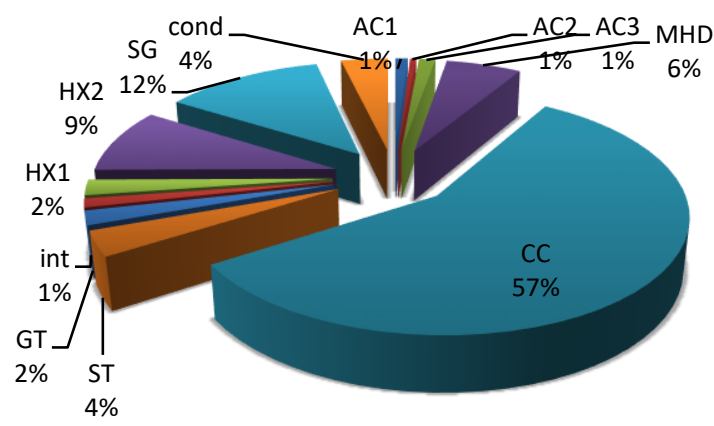

Figure 2. Exergy destruction distribution of the equipment 
Table 6. Thermodynamic and exergoeconomic data of all streams of combined cycle power plant integrated with MHD

\begin{tabular}{|c|c|c|c|c|c|c|c|}
\hline 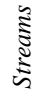 & $\cong \frac{\tilde{n}}{\approx}$ & $+\Sigma$ & $=\frac{\pi}{\bar{z}}$ & 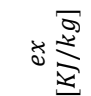 & 这变 & $\cup \underset{E}{E}$ & $\cdot \underset{\triangleq}{\sum}$ \\
\hline 1 & 17.34 & 300.0 & 100.0 & 0.00 & 0.00 & 0.000 & 0.00 \\
\hline 2 & 17.34 & 494.6 & 500.0 & 183.3 & 3180.6 & 36.88 & 422.3 \\
\hline 3 & 17.34 & 354.1 & 495.0 & 142.0 & 2464.7 & 36.88 & 327.3 \\
\hline 4 & 17.34 & 440.3 & 990.0 & 222.7 & 3862.9 & 36.92 & 513.5 \\
\hline 5 & 17.34 & 827.6 & 980.1 & 420.5 & 7295.5 & 32.89 & 863.8 \\
\hline 6 & 0.998 & 300.0 & 2068 & 51902 & 51824 & 6.50 & 1212.7 \\
\hline 7 & 18.34 & 3000 . & 960.5 & 2547.6 & 46734 & 19.94 & 3354.8 \\
\hline 8 & 18.34 & 2096.6 & 102.0 & 1421.3 & 26073 & 19.94 & 1871.6 \\
\hline 9 & 18.34 & 1259.3 & 101.0 & 619.7 & 11368 & 19.940 & 816.0 \\
\hline 10 & 18.34 & 418.0 & 100.0 & 21.6 & 397.1 & 19.940 & 28.5 \\
\hline 11 & 17.67 & 300.0 & 100.0 & 0.0 & 0.00 & 0.000 & 0.00 \\
\hline 12 & 17.67 & 610.2 & 1000.0 & 295.8 & 5228.7 & 27.88 & 524.7 \\
\hline 13 & 17.67 & 1623.0 & 990.00 & 1017.2 & 17977 & 24.532 & 1587.6 \\
\hline 14 & 17.67 & 915.45 & 101.01 & 282.75 & 4997.1 & 24.532 & 441.31 \\
\hline 15 & 17.67 & 535.37 & 100.00 & 61.86 & 1093.3 & 24.532 & 96.55 \\
\hline 16 & 5.75 & 318.82 & 10.00 & 2.31 & 13.29 & 33.781 & 1.62 \\
\hline 17 & 5.75 & 319.05 & 4000.00 & 6.34 & 36.42 & 41.517 & 5.44 \\
\hline 18 & 5.75 & 420.09 & 4000.00 & 84.61 & 486.22 & 59.937 & 104.91 \\
\hline 19 & 5.75 & 911.57 & 4000.00 & 1528.0 & 8780.8 & 28.296 & 894.45 \\
\hline 20 & 5.75 & 318.81 & 10.00 & 139.91 & 804.05 & 28.296 & 81.90 \\
\hline 21 & 159.22 & 300.00 & 200.00 & 0.1001 & 15.952 & 0.000 & 0.00 \\
\hline 22 & 159.22 & 320.00 & 180.00 & 2.7479 & 437.53 & 0.000 & 0.00 \\
\hline
\end{tabular}

Also, we calculated some other important parameters as $\dot{C}_{D}$. this parameter show the cost of exergy destruction in each component of the power cycle.

Table 7. Investment cost rate, exergoeconomic factor, relative cost difference and the exergy destruction cost rate of the equipment.

\begin{tabular}{lcccc}
\hline Component & $\dot{Z}[\$ / h r]$ & $f[\%]$ & $r[\%]$ & $\dot{C}_{D}[\$ / h r]$ \\
\hline Air Compressor 1 & 3.2141 & 11.08 & 7.37 & 25.79 \\
Air Compressor 2 & 0.5537 & 4.17 & 7.67 & 12.71 \\
Air Compressor 3 & 9.3702 & 26.61 & 7.19 & 25.84 \\
MHD & 915.02 & 90.93 & 72.29 & 91.26 \\
Combustion & 1278.3 & 74.61 & 104.37 & 435.05 \\
Chamber & 9.3945 & 10.89 & 11.73 & 76.88 \\
Steam Turbine & 29.1314 & 43.70 & 6.01 & 37.54 \\
Gas Turbine & 4.4080 & 11.09 & 66.52 & 35.33 \\
Intercooler & 5.5708 & 11.81 & 15.56 & 41.61 \\
Heat Exchanger 1 & 7.3143 & 4.95 & 16.14 & 140.42 \\
Heat Exchanger 2 & 1.9703 & 1.01 & 32.60 & 192.14 \\
Steam Generator & 0.9624 & 0.70 & 88.18 & 37.48 \\
Condenser & 0.9118 & 76.31 & 45.38 & 0.283 \\
Pump &
\end{tabular}

The results of the exergoeconomic analysis in Table 7 show that the exergy destruction of the combustion chamber causes a waste of $\$ 435.05$ per hour, and it is better to be reduced. In addition, the MHD exergoeconomic factor is $90.93 \%$, which indicates that the cost of this equipment is high compared to the cost of its exergy destruction. Thus, the cost of investing in this equipment can be reduced. Also, converters, compressors 1 and 2, steam turbine and condenser have a relatively low exergy quantification coefficients, which indicates that the exergy destruction to the equipment is costly. Therefore, increasing the thermodynamic efficiency of this equipment can be suggested as a solution. MHD's equipment requires high temperatures for optimal operation. Therefore, considering this point together, a slight decrease in the temperature of this stream can be considered. Furthermore, the cost of power generated in the MHD system is 12.36 cents per kilowatthour compared with the system similar to the same functional specification, and the operation of the gas turbine is 23.51 cents per kilowatt-hour, which can be due to the high cost of the turbine gas is available at working conditions. Therefore, we conclude that the MHD system is capable of cost-effective operation at high temperatures.

\subsection{Environmental Analysis}

Measuring the flow and concentration of exhaust gases from the outlet causes the determination of the mass of the pollutants in the unit time. This is directly related to detect and measure the air quality. Table 8 compares the pollutants released from a case without MED generator and the case study of this project.

Table 8. The emission rate of the pollutants in the presented scheme and those of the case using GT rather than MHD in $\mathrm{Kg} / \mathrm{hr}$

\begin{tabular}{lcc}
\hline Pollutant & Presented scheme & the case without $\mathrm{MHD}$ \\
\hline $\mathrm{CO}$ & 3.5982 & 3.6315 \\
$\mathrm{NO}_{x}$ & 8.6357 & 8.7157 \\
$\mathrm{CO}_{2}$ & 2559.2 & 2582.9 \\
\hline
\end{tabular}

The results of emission analysis show that a system that uses MHD has a lower emission rate. Also, the exergy efficiency of this system increases with the use of MHD instead of the gas turbine from $54.71 \%$ to 55.47 . The MHD also can operate at high temperatures, while the gas turbine has limited blasting capacity, and expensive.

\section{Conclusions}

A combined cycle power plant has been integrated with MHD generator, and the integrated plant has analyzed thermodynamically, for exergetic, exergoeconomic, and environmental impacts. The integrated plant has higher efficiency than the combined cycle power plant. The MHD generator increases efficiency lowers environmental emission and cost of the exergy destruction. The magnetohydrodynamic power generation system may be the main source of energy production in near future. 


\section{APPENDIX A}

Table A. Equations, inputs, and outputs of the equipment

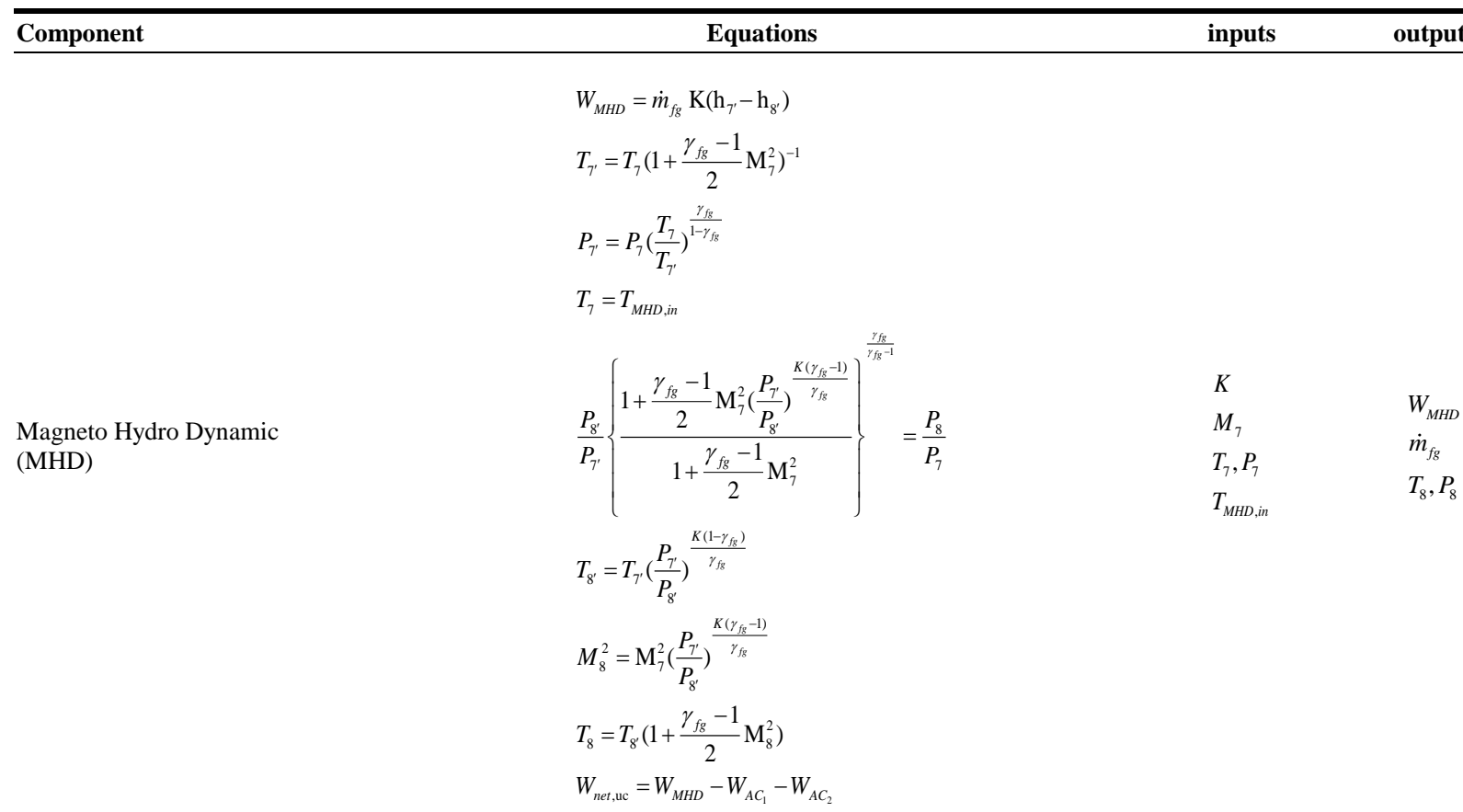

Air Compressor 1

$$
\begin{aligned}
& W_{A C_{1}}=\dot{m}_{u c}\left(\mathrm{~h}_{2}-\mathrm{h}_{1}\right) \\
& \mathrm{T}_{1}=T_{0} \\
& P_{1}=P_{0}
\end{aligned}
$$$$
P_{2}=P_{1} \times r_{p, A C}
$$$$
T_{2}=T_{1}\left\{1+\frac{1}{\eta_{A C_{1}}}\left[\mathrm{r}_{p, A C_{1}}{ }^{\frac{\gamma_{a i r}-1}{\gamma_{a i r}}}-1\right]\right\}
$$$$
h_{1}=h_{\text {air } @ T_{1}}, h_{2}=h_{\text {air } @ T_{2}}
$$$$
W_{A C_{2}}=\dot{m}_{u c}\left(\mathrm{~h}_{4}-\mathrm{h}_{3}\right)
$$$$
P_{4}=P_{3} \times r_{p, A C}
$$

Air Compressor 2

Air Compressor 3

Combustion Chamber
$T_{4}=T_{3}\left\{1+\frac{1}{\eta_{A C_{2}}}\left[\mathrm{r}_{p, A C_{2}} \frac{\gamma_{\text {air }}-1}{\gamma_{a i r}}-1\right]\right\}$

$$
h_{4}=h_{\text {air } @ T_{4}}
$$

$W_{A C_{3}}=\dot{m}_{l c}\left(\mathrm{~h}_{12}-\mathrm{h}_{11}\right)$

$\mathrm{T}_{11}=T_{0}$

$P_{11}=P_{0}$

$P_{12}=P_{11} \times r_{p, A C_{3}}$

$T_{12}=T_{11}\left\{1+\frac{1}{\eta_{A C_{3}}}\left[\mathrm{r}_{p, A C_{3}}{ }^{\frac{\gamma_{\text {air }}-1}{\gamma_{\text {air }}}}-1\right]\right\}$

$h_{11}=h_{\text {air } @ T_{11}}, h_{12}=h_{\text {air } @ T_{12}}$

$\dot{m}_{u c} h_{5}+\dot{m}_{f} L H V_{f u e l} \eta_{C C}-\dot{m}_{f g} h_{7}=0$

$\dot{m}_{u c}+\dot{m}_{f}-\dot{m}_{f g}=0$

$P_{7}=P_{5}\left(1-\Delta \mathrm{P}_{C C}\right)$

$h_{7}=h_{\mathrm{fg} @ T_{7}}$
$T_{0}, \mathrm{P}_{0}$

$r_{p, A C_{1}}$

$\eta_{A C_{1}}$

$c_{a i r}, \gamma_{\text {air }}$

$W_{A C_{1}}$

$\dot{m}_{u c}$

$T_{2}, P_{2}$

$T_{3}, \mathrm{P}_{3}$

$r_{p, A C_{2}}$

$\eta_{A C_{2}}$

$c_{\text {air }}, \gamma_{\text {air }}$

$W_{A C_{2}}$

$\dot{m}_{u c}$

$T_{4}, P_{4}$

$T_{0}, \mathrm{P}_{0}$

$r_{p, A C_{3}}$

$\eta_{A C_{3}}$

$c_{\text {air }}, \gamma_{\text {air }}$

$W_{A C_{3}}$

$\dot{m}_{l c}$

$T_{12}, P_{12}$

$\begin{array}{ll}L H V_{f u l}, \eta_{C C} & Q_{C C} \\ \Delta P_{C C} & P_{7} \\ T_{5}, P_{5} & \dot{m}_{u c}, \dot{m}_{f}, \dot{m}_{f g}\end{array}$




\begin{tabular}{|c|c|c|c|}
\hline Intercooler & $\begin{array}{l}\dot{m}_{u c}\left(h_{2}-h_{3}\right)+\dot{m}_{s c}\left(h_{17}-\mathrm{h}_{18}\right)=0 \\
P_{3}=P_{2}-\Delta P_{\text {int,uc }} \\
P_{18}=P_{17}-\Delta P_{\text {int,sc }} \\
\varepsilon_{\text {int }}=\frac{Q_{\text {int }}}{Q_{\text {int,max }}} \\
Q_{\text {int }}=\dot{m}_{s c}\left(\mathrm{~h}_{18}-\mathrm{h}_{17}\right) \\
\mathrm{Q}_{\mathrm{int,max}=}\left(\dot{\mathrm{mc}}_{p}\right)_{\min } \times \Delta T_{\max } \\
h_{3}=h_{\text {air } @ T_{3}}, \mathrm{~h}_{18}=h_{\text {water } @ T_{18}, P_{18}}\end{array}$ & $\begin{array}{l}T_{2}, P_{2} \\
\Delta P_{\text {int,uc }} \\
\Delta P_{\text {int,sc }} \\
\varepsilon_{\text {int }} \\
T_{17}, P_{17}\end{array}$ & $\begin{array}{l}Q_{\mathrm{int}} \\
T_{3}, P_{3} \\
T_{18}, P_{18} \\
\dot{m}_{u c}, \dot{m}_{s c}\end{array}$ \\
\hline Heat Exchanger 1 & $\begin{array}{l}\dot{m}_{u c}\left(h_{4}-h_{5}\right)+\dot{m}_{l c}\left(h_{14}-\mathrm{h}_{15}\right)=0 \\
P_{5}=P_{4}-\Delta P_{\mathrm{HX}_{1}, \mathrm{uc}} \\
P_{15}=P_{0} \\
\varepsilon_{H X_{1}}=\frac{Q_{H X_{1}}}{Q_{\mathrm{HX}_{1}, \max }} \\
Q_{H X_{1}}=\dot{m}_{l c}\left(\mathrm{~h}_{14}-\mathrm{h}_{15}\right) \\
\mathrm{Q}_{\mathrm{HX}_{1}, \max =}\left(\dot{\mathrm{mc}}_{p}\right)_{\min } \times \Delta T_{\max } \\
h_{5}=h_{\text {air } @ T_{5}}, \mathrm{~h}_{15}=h_{\text {air } @ T_{15}}\end{array}$ & $\begin{array}{l}T_{4}, P_{4} \\
\Delta P_{\mathrm{HX}_{1}, \text { uc }} \\
\Delta P_{\mathrm{HX}_{1}, \mathrm{lc}} \\
\varepsilon_{H X_{1}} \\
T_{14}, P_{14}\end{array}$ & $\begin{array}{l}Q_{H X_{1}} \\
T_{5}, P_{5} \\
T_{15}, P_{15} \\
\dot{m}_{u c}, \dot{m}_{l c}\end{array}$ \\
\hline Heat Exchanger 2 & $\begin{array}{l}\dot{m}_{f g}\left(h_{8}-h_{9}\right)+\dot{m}_{l c}\left(h_{12}-\mathrm{h}_{13}\right)=0 \\
P_{9}=P_{8}-\Delta P_{\mathrm{HX}_{2}, \mathrm{uc}} \\
P_{13}=P_{12}-\Delta P_{\mathrm{HX}_{2}, \mathrm{lc}} \\
\varepsilon_{H X_{2}}=\frac{Q_{H X_{2}}}{Q_{\mathrm{HX}_{2}, \max }} \\
Q_{H X_{2}}=\dot{m}_{l c}\left(\mathrm{~h}_{13}-\mathrm{h}_{12}\right) \\
\mathrm{Q}_{\mathrm{HX}_{2}, \max =}\left(\dot{m c}_{p}\right)_{\min } \times \Delta T_{\max } \\
T_{13}=T I T \\
h_{9}=h_{\mathrm{fg} @ T_{9}}, \mathrm{~h}_{13}=h_{\mathrm{fg} @ T_{13}}\end{array}$ & $\begin{array}{l}T_{8}, P_{8} \\
\Delta P_{\mathrm{HX}_{2}, \mathrm{uc}} \\
\Delta P_{\mathrm{HX}_{2}, \mathrm{lc}} \\
T I T \\
T_{12}, P_{12}\end{array}$ & $\begin{array}{l}Q_{H X_{2}} \\
\varepsilon_{H X_{2}} \\
T_{9}, P_{9} \\
T_{13}, P_{13} \\
\dot{m}_{f g}, \dot{m}_{l c}\end{array}$ \\
\hline Steam Generator & $\begin{array}{l}\dot{m}_{f g}\left(h_{9}-h_{10}\right)+\dot{m}_{s c}\left(h_{18}-\mathrm{h}_{19}\right)=0 \\
P_{19}=P_{18}-\Delta P_{\mathrm{SG}, s c} \\
P_{10}=P_{0} \\
\varepsilon_{S G}=\frac{Q_{S G}}{Q_{\mathrm{SG}, \max }} \\
Q_{S G}=\dot{m}_{s c}\left(\mathrm{~h}_{19}-\mathrm{h}_{18}\right) \\
\mathrm{Q}_{\mathrm{SG}, \text { max }}\left(\dot{\mathrm{m}}_{p}\right)_{\min } \times \Delta T_{\max } \\
h_{19}=h_{\text {water } @ T_{19}, P_{19}}, \mathrm{~h}_{10}=h_{\mathrm{fg} @ T_{10}}\end{array}$ & $\begin{array}{l}T_{9}, P_{9} \\
\Delta P_{\mathrm{SG}, \mathrm{uc}} \\
\Delta P_{\mathrm{SG}, \mathrm{sc}} \\
\varepsilon_{S G} \\
T_{18}, P_{18}\end{array}$ & $\begin{array}{l}Q_{S G} \\
T_{10}, P_{10} \\
T_{19}, P_{19} \\
\dot{m}_{f g}, \dot{m}_{s c}\end{array}$ \\
\hline Steam Turbine & $\begin{array}{l}\dot{m}_{s c}\left(h_{19}-h_{20}\right)-W_{S T}=0 \\
\eta_{S T}=\frac{h_{19}-h_{20}}{h_{19}-h_{20 s}} \\
\mathrm{P}_{20}=P_{c o n d} \\
W_{\text {net }, \mathrm{sc}}=W_{S T}-W_{\text {Punp }}\end{array}$ & $\begin{array}{l}T_{19}, P_{19} \\
\eta_{S T} \\
P_{\text {cond }}\end{array}$ & $\begin{array}{l}W_{S T} \\
\dot{m}_{s c} \\
T_{20}, P_{20}\end{array}$ \\
\hline Condenser & $\begin{array}{l}Q_{\text {cond }}=\dot{m}_{s c}\left(\mathrm{~h}_{20}-\mathrm{h}_{16}\right) \\
P_{16}=P_{20}-\Delta P_{\text {cond }} \\
T_{16}=T_{\text {sat,water } @ P_{16}}\end{array}$ & $\begin{array}{l}T_{20}, P_{20} \\
\Delta P_{\text {cond }}\end{array}$ & $\begin{array}{l}Q_{\text {cond }} \\
T_{16}, P_{16}\end{array}$ \\
\hline Pump & $\begin{array}{l}W_{\text {Pump }}=\dot{m}_{s c}\left(\mathrm{~h}_{17}-\mathrm{h}_{16}\right) \\
\eta_{\text {Pump }}=\frac{h_{17 s}-h_{16}}{h_{17}-h_{16}} \\
\mathrm{P}_{17}=P_{H P}\end{array}$ & $\begin{array}{l}T_{16}, P_{16} \\
P_{H P} \\
\eta_{\text {Pump }}\end{array}$ & $\begin{array}{l}T_{17}, P_{17} \\
W_{\text {Pump }}\end{array}$ \\
\hline
\end{tabular}




\section{Nomenclature}

\begin{tabular}{|c|c|c|c|}
\hline $\mathrm{AC}$ & Air Compressor & SG & Steam Generator \\
\hline $\mathrm{AF}$ & Amount of the Fuel & ST & Steam Turbine \\
\hline $\mathrm{CC}$ & Combustion Chamber & $\mathrm{T}$ & Temperature \\
\hline cond & Condenser & TIT & Turbine Inlet Temperature \\
\hline$c_{p}$ & $\begin{array}{l}\text { specific heat at constant } \\
\text { pressure }\end{array}$ & $\dot{W}$ & work \\
\hline$\dot{C}$ & Cost rate & $x_{k}$ & mole fraction \\
\hline $\mathrm{c}$ & Cost per exergy unit & $\mathrm{Z}$ & Cost rate of the equipment \\
\hline $\mathrm{CRF}$ & Capital Recovery Factor & \multicolumn{2}{|c|}{ Greek Letters } \\
\hline $\mathrm{E}$ & Emission rate & $\alpha$ & $\begin{array}{l}\text { Ratio of molar masses of } \\
\mathrm{CO}_{2} \text { and } \mathrm{C}\end{array}$ \\
\hline$\dot{E}$ & Energy rate & $\gamma$ & ratio of the specific heats \\
\hline $\mathrm{EF}$ & Emission Factor & $\Delta$ & Difference \\
\hline ER & $\begin{array}{l}\text { Effectiveness of the } \\
\text { Emission reduction }\end{array}$ & $\varepsilon$ & Effectiveness \\
\hline ex & Specific exergy & $\eta$ & Efficiency \\
\hline$\dot{E} x$ & Exergy rate & $\varphi$ & Maintenance factor \\
\hline $\mathrm{f}$ & Exergo-economic factor & $\psi$ & Exergetic Efficiency \\
\hline GT & Gas Turbine & \multicolumn{2}{|c|}{ Subscripts } \\
\hline $\mathrm{h}$ & Enthalpy & $\mathrm{D}$ & Destruction \\
\hline $\mathrm{HX}$ & Heat Exchanger & fg & Flue gas \\
\hline $\mathrm{i}$ & Interest rate & $\mathrm{f}$ & Fuel \\
\hline$\dot{m}$ & Mass Flow Rate & $\mathrm{k}$ & $\mathrm{k}^{\text {th }}$ component \\
\hline MHD & Magneto hydrodynamic & $\mathrm{L}$ & Loss \\
\hline $\mathrm{n}$ & Plants life & lc & Lower cycle \\
\hline $\mathrm{N}$ & Operating hours & $\mathrm{p}$ & Product \\
\hline $\mathrm{P}$ & Pressure & sat & Saturated \\
\hline PEC & Purchased Equipment Cost & $\mathrm{sc}$ & Steam cycle \\
\hline Q & Heat Duty & uc & Upper cycle \\
\hline $\bar{R}$ & Universal Gas Constant & \multicolumn{2}{|c|}{ Superscripts } \\
\hline$r_{p}$ & Pressure ratio & $\mathrm{CH}$ & Chemical \\
\hline s & Entropy & PH & Physical \\
\hline
\end{tabular}

\section{References}

[1] J. D.Aspnes, D. A.Pierre, "Magnetohydrodynamic/ steam power plant modeling and control," Energy Conversion, vol. 18, pp. 101-113, 1978.

[2] N. Chaturvedi, "A study of polarization in MHD power generator," Energy Conversion and Management, vol. 30, pp. 49-53, 1990.

[3] V. R.Malghan, "Prospects of early commercialization of MHD power plants," Energy Conversion and Management, vol.30, pp. 267-275, 1990.

[4] M. Ishikawa, M. Fujita, Y. Fujita and J. Umoto, "Performance of coal-fired MHD generators with large leakage current," Energy Conversion and Management, vol.34, pp. 607-617, 1993.

[5] N. Lemnean, I. Dogaru, L. Katona, and M. Cardu, “On the achievement of some experimental MHD power generators," Energy Conversion and Management, vol. 35, pp. 87-90, 1994.

[6] M. Ishikawa, Y. Inui, J. Umoto, K. Yoshikawa, "Preliminary analysis of MHD - Brayton cycle applied to fusion reactors (CFAR)," Fusion Engineering and Design, vol. 29, pp. 57-63, 1995.

[7] M. Ishikawa, T. Matsuo, J. Umoto, "Stability analysis of MHD disk generators and application to power systems with CO2 recovery," Energy, vol. 22, pp. 239-247, 1997.

[8] M. Ishikawa, M. Steinberg, "MHD power systems for reduction of $\mathrm{CO} 2$ emission," Energy Conversion and Management, vol. 39, pp. 529-539, 1998.

[9] Bhadoria, B., Chandra A., "Losses in diagonal MHD generator," Energy Conversion and Management, vol. 40, pp. 1985-1995, 1999.

[10] N. Kayukawa, "Comparisons of MHD topping combined power generation systems," Energy Conversion and Management, vol. 41, pp. 1953-1974, 2000.

[11] Y. Inui, H. Ito, T. Ishida, "Two dimensional simulation of closed cycle disk MHD generator considering nozzle and diffuser," Energy Conversion and Management, vol. 45, pp. 1993-2004, 2004.

[12] L. Chen, J. Gong, F. Sun, C. Wu, "Heat transfer effect on the performance of MHD power plant," Energy Conversion and Management, vol. 43, pp. 2085-2095, 2002.

[13] I. Inoue, Y. Inui, N. Hayanose, M. Ishikawa, Transient stability analysis of commercial scale open cycle disk MHD generator connected to power system," Energy Conversion and Management, vol. 44, pp. 731-741, 2003.

[14] C. Vogin, A. Alemany, "Analysis of the flow in a thermo-acoustic MHD generator with conducting walls," European J. Mechanics-B/ Fluids, vol. 26, pp. 479-493, 2007.

[15] S. P.Cicconardi, A. Perna, "Performance analysis of integrated systems based on MHD generators," Energy Procedia, vol. 45, pp. 1305-1314, 2014.

[16] D. Sarkar, Thermal power plant: design and operation, $1^{s t} E d$. Elsevier, 2015.

[17] A. O.Ayeleso, M. Kahn, "Modelling of a combustible ionised gas in thermal power plants using MHD conversion system in South Africa," J. of King Saud University-Science, vol. 30, pp. 367-374, 2018.

[18] H. K.Messerle, Magnetohydrodynamic Electrical Power Generation, New York: Wiley, 1995.

[19] A. Valero, et al., "CGAM problem: Definition and conventional solution", Energy, vol. 19, 279-286, 1994.

[20] A. Bejan, G. Tsatsaronis, M. Moran, Thermal Design and Optimization, New York: Wiley, 1996.

[21] I. Dincer, M. A.Rosen, and P. Ahmadi, Optimization of Energy Systems, New York: Wiley, 2017.

[22] R. K.Shah, D. P.Sekulic, Fundamentals of Heat Exchanger Design, Wiley, 2003.

[23] F. A.Boyaghchi, P. Heidarnejad, "Thermoeconomic assessment and multi objective optimization of a solar micro CCHP based on Organic Rankine Cycle for domestic application," Energy Conversion and Management, vol. 97: pp. 224-234, 2015.

[24] M. Sadeghi, et al., "Thermoeconomic optimization using an evolutionary algorithm of a trigeneration system driven by a solid oxide fuel cell," Energy, vol. 89, 191204, 2015. 
[25] H. Ghaebi, M.H. Saidi, and P. Ahmadi, "Exergoeconomic optimization of a trigeneration system for heating, cooling and power production purpose based on TRR method and using evolutionary algorithm," Applied Thermal Engineering, vol. 36, pp. 113-125, 2012.

[26] A.E. Sheindlin, et al., "Magnetohydrodynamic Power Generation," Natural Resources Forum, doi: 10.1111/j.1477-8947.1979.tb00402.x

[27] Federal Reserve Bank of Minneapolis - Consumer Price Index. Available from:

https://www.minneapolisfed.org/community/financial-andeconomic-education/cpi-calculator-information/consumerprice-index-and-inflation-rates-1913.
[28] M. Gadalla, Z. Olujic, M. Jobson, R. Smith, "Estimation and reduction of $\mathrm{CO} 2$ emissions from crude oil distillation units," Energy, vol. 31, 2398-2408, 2006.

[29] SYKE - air pollutant emission factor library Available from: http://www.apef-library.fi.

[30] U.S. environmental protection agency- technology transfer network- clearinghouse for inventories and emission factors. Available from :www3.epa.gov/ttnchie1/ap42/.

[31] M.E. Nimvari, A. Hadidi, "Analysis of triple combined cycle with MHD generator as a topping cycle," American J. of Advanced Scientific Research, vol. 1, pp. 21-28, 2012. 